\title{
PENGARUH MODEL PEMBELAJATAN GUIDED INQUIRY TERHADAP HASIL BELAJAR SISWA KELAS VIII PADA SPLDV DI PONPES AI-YISIFIYAG
}

\author{
Oleh : \\ Isra Novidayanti Matondang, Yuni Rhamayanti, Puspa Riani Nasution \\ Universitas Graha Nusantara
}

\begin{abstract}
Abstrak
Salah satu yang harus diperhatikan dalam pembelajaran matematikaadalah Model atau metode yang digunakan dakam proses pembekajaran, karena metode mempunyai peranan yang penting dalam menentukan keberhasilan siswa. Penelitian ini ditujukan untuk mengetahui adakah pengaruh motivasi dan minat belajar siswa terhadap hasil belajar pada pokok bahasan persamaan liniear satu variabel. Populasi dalam penelitian ini adalah adalah siswa kelas VIII Ponpes AlYusufiyah, dengan jumlah kelas VIII sebanyak 7 kelas. Pada penelitian ini sampel diambil dari populasi dengan teknik ClusterRandom Sampling yaitu penelitinmengambil sampelnya berdasarkan daerah populasi yang telah ditetapkan. Jumlah sampel adalah 20 siswa.Metode pengumpulan data yang digunakan pada penelitian ini adalah metode kuisioner dan dokumentasi. Untuk analisis data akhir menggunakan Regresi Linier Sederhana. Konstanta (a) sebesar 36,714 artinya jika variabel tingkat Pengaruh Guided adalah 0, maka variabel volume Hasil belajar nilainya 36,714.Koefisien regresi variabel Guided Inquiry bernilai positif sebesar 13,671 menunjukkan bahwa apabila hasil belajar meningkat 1 (satuan) maka cara hasil belajar mengalami peningkatan sejumlah 13,671 koefisien bernilai positif artinya terjadi hubungan positif antara Guided Inquiry dan Hasil Belajar. Kata Kunci: Pengaruh Guided, Hasil Belajar
\end{abstract}

Abstract

One thing that must be considered in learning mathematics is the model or method used in the learning process, because the method has an important role in determining student success. This study aimed to determine whether there is an effect of student motivation and interest in learning on learning outcomes on the subject of linear equations of one variable. The population in this study were students of class VIII Ponpes Al-Yusufiyah, with the number of class VIII as many as 7 classes. In this study, the sample was taken from the population using the Cluster Random Sampling technique, namely the research took the sample based on a predetermined population area. The number of samples is 20 students. The data collection method used in this study is a questionnaire and documentation method. For the final data analysis using Simple Linear Regression. The constant (a) is 36.714, meaning that if the Guided Effect level variable is 0 , then the volume variable for learning outcomes is 36,714. The regression coefficient of the Guided Inquiry variable has a positive value of 13.671 indicating that if the learning outcomes increase by 1 (unit), then the way the learning outcomes increase by 13.671 coefficients is positive, meaning that there is a positive relationship between Guided Inquiry and Learning Outcomes.

Keywords: Guided Effect, Learning Outcomes

\section{PENDAHULUAN}

Pendidikan merupakan usaha sadar melaui proses bimbingan, latihan, dan pengajaran yang bertujuan untuk mengantarkan para siswa menuju kepada perubahan tingkah laku. Pendidikan di sekolah harus dilaksanakan sebaik mungkin agar proses kegiatan belajar mengajar berlangsung efektif. Seperti yang diamanatkan dalam Undang-Undang tahun 2003, bahwa: "Pendidikan Nasional berfungsi mengembangkan kemampuan dan mencerdaskan kehidupan bangsa, bertujuan untuk berkembangnya potensi peserta didik agar menjadi manusia yang beriman dan bertawa kepada Tuhan yang Maha Esa, berakhlak mulia, sehat, berilmu, cakap, kreatif, mandiri menjadi warga negara yang demokratis dan bertanggung jawab". Proses pembelajaran dapat direkayasa sedemikian rupa oleh guru dengan menerapkan rancangan pembelajaran selama ini kurang menarik bagi siswa karena didominasi dengan metode ceramah (Sagala, 2011, h.12).

Melalui penerapan model pembelajaran Guided Inquiry pada materi SPLDV, guru dapat mengembangkan kemampuan berfikir dan penalaran siswa, sehingga siswa dengan eksperimeneksperimen sederhana dan serangkaian pertanyaan yang mensitumuls rasa keingintahuan siswa, 
ISSN. 2621-9832

JURNAL MathEdu (Mathematic Education Journal) http://journal.ipts.ac.id/index.php/MathEdu Vol. 4 No. 3 November 2021

sehingga siswa akan merasa tertarik untuk melakukan percobaan, pengamatan, dan dari hasil pengamatan serta pemahamannya, dapat diterapkan kembali dalam kehidupan sehari-hari. Dengan demikian, model pembelajaran guided inquiry dapat menjadikan pelajaran matematika lebih menarik, mudah dipahami, dan dapat meningkatkan hasil belajar dan pemahaman siswa.

Berdasarkan uraian diatas, maka penulis ingin mengetahui lebih lanjut mengenai penelitian yang berjudul "Pengaruh Model Pembelajaran Guided InquiryTerhadap Hasil Belajar Siswa Pada Pokok Bahasan Sistem Linear dua Variabel di Ponpes Al-yusufiyah Kecamatan Batang AngkolaTahun Ajaran 2020/2021”.

\section{METODE PENELITIAN}

Penelitian ini akan dilaksanakan di Ponpes Al-Yusufiyah Kecamatan Batang Angkola kelas VIII semester gassal Tahun Ajaran 2020/2021 alasan penelitian memilih lokasi penelitian disekolah ini adalah karena belum ada yang meneliti mengenai permasalahan yang sama disekolah tersebut. Sehubungan dengan hal tersebut waktu pelaksanakan penelitian setelah proposal diseminarkan.

Tabel 1 Rencana Tempat dan Waktu Penelitian

\begin{tabular}{|c|c|c|c|}
\hline Hari/Tanggal & Pukul & Perlakuan & Lokasi \\
\hline $\begin{array}{lll}\text { Senin } & 27 & \text { Juli } \\
2020 & & \end{array}$ & $08.30-10.30$ & $\begin{array}{l}\text { Uji Coba Tes pada Soal } \\
\text { pretest }\end{array}$ & $\begin{array}{lr}\text { Ponpes } & \text { Al-Yusufiyah } \\
\text { Kecamtan } & \text { Batang } \\
\text { Angkola } & \\
\end{array}$ \\
\hline $\begin{array}{l}\text { Selasa } 28 \text { Juli } \\
2020\end{array}$ & $08.30-11.00$ & $\begin{array}{l}\text { Uji Coba Test pada Soal } \\
\text { Pretest }\end{array}$ & $\begin{array}{lr}\text { Ponpes } & \text { Al-Yusufiyah } \\
\text { Kecamatan } & \text { Batang } \\
\text { Angkola } & \\
\end{array}$ \\
\hline $\begin{array}{lll}\text { Rabu } & 29 & \text { Juli } \\
2020 & & \end{array}$ & $08.30-10.30$ & $\begin{array}{l}\text { Pembelajaran dengan } \\
\text { Metode Ceramah }\end{array}$ & $\begin{array}{lr}\text { Kelas Kontrol } & \text { (VIII-E } \\
\text { Ponpes } & \text { Al-Yusufiyah } \\
\text { Kecamatan } & \text { Batang } \\
\text { Angkola) } & \\
\end{array}$ \\
\hline $\begin{array}{l}\text { Kamis } 30 \text { Juli } \\
2020\end{array}$ & $08.30-11.00$ & $\begin{array}{l}\text { Pembelajaran dengan } \\
\text { Metode ceramah } \\
\text { Soal Postest }\end{array}$ & $\begin{array}{lr}\text { Kelas Kontrol } \text { (VIII- E } \\
\text { Ponpes } & \text { Al-Yusufiyah } \\
\text { Kecamatan } & \text { Batang } \\
\text { Angkola) } & \\
\end{array}$ \\
\hline $\begin{array}{lr}\text { Sabtu } & 1 \\
\text { Agustus } & 2020\end{array}$ & $08.00-11.00$ & $\begin{array}{l}\text { Pembelajaran dengan } \\
\text { Metode GuidedInquiry }\end{array}$ & $\begin{array}{lr}\text { Kelas Eksperimen (VIII-F } \\
\text { Ponpes } & \text { Al-Yusufiyah } \\
\text { Kecamatan } & \text { Batang } \\
\text { Angkola) } & \\
\end{array}$ \\
\hline $\begin{array}{lr}\text { Senin } & 3 \\
\text { Agustus } & 2020\end{array}$ & $08.00-11.00$ & $\begin{array}{l}\text { Pembelajaran dengan } \\
\text { Model Guided Inquiry } \\
\text { Soal Posttest }\end{array}$ & $\begin{array}{lr}\text { Kelas Eksperimen (VIII-F } \\
\text { Ponpes Al-Yusufiyah } \\
\text { Kecamatan } \\
\text { Angkola) }\end{array}$ \\
\hline
\end{tabular}

Populasi dari penelitian ini adalah seluruh siswa Ponpes Al-Yusufiyah Kecamatan Batang Angkola dengan populasi sasarannya adalah seluruh siswa kelas VIII di sekolah yang sama.

Tabel 2. Populasi Siswa Ponpes Al-Yusufiyah Kecamatan Batang Angkola

\begin{tabular}{lll}
\hline No & Kelas & Jumlah \\
\hline 1 & VIII-A & 24 \\
\hline 2 & VIII-B & 25 \\
\hline 3 & VIII-C & 28 \\
\hline 4 & VIII-D & 26 \\
\hline 5 & VIII-E & 22 \\
\hline 6 & VIII-F & 20 \\
\hline
\end{tabular}

\section{Hasil Penelitian}

Instrumen yang digunakan pada penelitian ini merupakan tes hasil belajar matematika berupa pretes dan postes masing-masing sebanyak 11 butir soal pada pokok bahasan sistem 
persamaan linear dua variabel dalam bentuk uraian yaitu Jika jawaban benar maka mendapat poin 1 (satu), dan jika jawaban salah mendapat nilai 0 (nol).

Pada kelas kontrol dengan materi pembelajaran matematika pada pokok bahasan sistem persamaan linear dua variabel. Dan diberikan penjelasan materi tentang sistem persamaan linear dua variabel dalam pembelajaran untuk melihat hasil belajar matematika siswa kelas VIII di Ponpes Al-Yusufiyah Kecamatan Batang Angkola. Diakhiri pembelajaran kelas kontrol yang dilaksanakan dengan pretes sebagai hasil belajar siswa matematika, maka hasil yang didapatkan dari pretes tersebut dapat dilihat pada tabel berikut ini:

Tabel 3 Pengklasifikasian Nilai Hasil Pretes Pada Kelas Kontrol

\begin{tabular}{|c|c|c|c|}
\hline Hasil Nilai & Jumlah Siswa & Persentase & Klasifikasi Nilai \\
\hline $9-10$ & 0 & $0 \%$ & Sangat Baik \\
\hline $7-8$ & 1 & $4,5 \%$ & Baik \\
\hline $5-6$ & 12 & $54,5 \%$ & Cukup \\
\hline $3-4$ & 9 & $41 \%$ & Kurang \\
\hline $1-2$ & 0 & $0 \%$ & Sangat Kurang \\
\hline Total & $\mathbf{2 2}$ & $\mathbf{1 0 0 \%}$ & \\
\hline
\end{tabular}

\section{Pembahasan}

Dari data yang diperoleh peneliti di lapangan menunjukkan bahwa adanya pengaruh Guided Inquiry terhadap hasil belajar siswa pada kelas eksperimen, yaitu meningkatnya hasil belajar siswa dengan melakukan perlakuan Guided Inquiry di kelas eksperimen. Kelas kontrol dan kelas eksperimen memiliki distribusi data yang normal dengan hasil perhitungan uji normalitas untuk soal pretes pada kelas kontrol diperoleh $\mathrm{L}_{0}\left(\mathrm{~L}_{\text {hitung }}\right)=0,000<0,281=\mathrm{L}_{(0,05 ; 22)}$, sedangkan untuk soal pretes pada kelas eksperimen dengan $\mathrm{L}_{0}=0,015<0,294 \mathrm{~L}_{(0,05 ; 20)}$. Hasil perhitungan uji normalitas

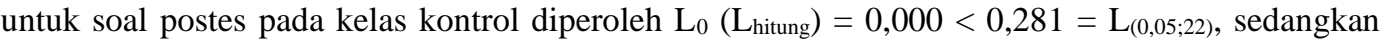
untuk soal postes pada kelas eksperimen dengan $\mathrm{L}_{0}=0,000<0,294 \mathrm{~L}_{(0,05 ; 20)}$. Setelah uji normalitas memberikan indikasi data hasil penelitian berdistribusi normal, maka dilanjutkan dengan uji homogenitas dari sampel penelitian.

\section{Kesimpulan}

Berasarkan hasil penelitian dan pembahasan diperoleh beberapa kesimpulan sebagai berikut: 1.Kelas control dan kelas eksperimen memiliki diistribusi data yang normal dengan hasil perhitungan uji normalitas untuk soal pretes pada kelas control diperoleh sedangkan untuk soal pretes pada kelas eksperimen dengan . Hasil perhitungan uji normalitas untuk soal postes pada kelas control iperoleh. sedangkan untuk soal posttest pada kelas eksperimen dengan 2. Pada uji homogenitas diperoleh hasil variansi yang homogeny ditunjukkan oleh hasilhomogenitas varians dimana keduanya memenuhi syarat sebagai obyek penelitian dengan menggunakan uji. 3. Terdapat pengaruh yang signifikan menggunakan model pembelajaran Guieded Inquiry terhadap hasil belajar siswa pada pokok bahasan system persamaan linear dua variabel di kelas VIII Ponpes Al-Yusufiyah Kecamatan Batang Angkola. 4. Hasil belajar Matenatika yang diajarkan dengan model Guided Inquiry memperoleh nilai yang lebih tinggi dibandingkan dengan metode ceramah.

\section{DAFTAR PUSTAKA}

Clark, (2014), Faktor-Faktor yang Mempengaruhi Hasil Belajar. Pustaka, Yogyakarta

Daryanto, (2018), Pengertian Hasil Belajar. Pustaka Belajar, Yogyakarta.

Djamarah, (2013), Strategi Belajar Mengajar, Bumi Aksara, Jakarta. , (2018), Pengertian Hasil Belajar, PT Rineka Cipta, Jakarta

Huda, Miftahul, (2017), Model-Model Pengajaran Dan Pembelajaran, Pustaka.

Nasution, (2018), Pengertian Belajan dan Hasil Belajar,

Purwanto, (2017), Evaluasi Hasil Belajar, Pustaka Belajar, Yogyakarta.

Nanang Hanafiyah, Cucu Suhana, Konsep Strategi Pembelajaran, Reflika Aditama. Bandung.

Paul, Suparno,2007. Metodologi Pembelajaran, P.T. Rineka Cipta, Bandung. 